\title{
Low-temperature crystallization of CSD-derived PZT thin film with laser assisted annealing
}

\author{
Takaharu MIYAZAKI, ${ }^{*, * *, \dagger}$ Setsu SOU, ${ }^{* *}$ Naonori SAKAMOTO, ${ }^{* *}$ Naoki WAKIYA ${ }^{* *}$ and Hisao SUZUKI* \\ ${ }^{*}$ Graduate School of Science and Technology, Shizuoka University, 3-5-1 Johoku, Hamamatsu-shi, Shizuoka 432-8561 \\ ** Department of Materials Science and Chemical Engineering, Shizuoka University, \\ 3-5-1 Johoku, Hamamatsu-shi, Shizuoka 432-8561 \\ ***Yasu Division, Murata Manufacturig, 2288 Oshinohara, Yasu-shi, Shiga, 520-2393
}

\begin{abstract}
Low temperature crystallization of CSD-derived ferroelectric thin films was aimed by laser assisted annealing in this paper. $\mathrm{Pb}\left(\mathrm{Zr}_{x} \mathrm{Ti}_{1-x}\right) \mathrm{O}_{3}(\mathrm{PZT})$ thin films with a MPB composition $(\mathrm{Zr} / \mathrm{Ti}=53 / 47)$ and $\mathrm{LaNiO}_{3}(\mathrm{LNO})$ thin film electrodes were deposited by the chemical solution deposition (CSD) method on a Si wafer. The thickness of PZT films was about $70 \mathrm{~nm}$, and the thickness of LNO films as seeding layers and electrodes was about $250 \mathrm{~nm}$. The PZT/LNO films were annealed at the substrate temperature ranging from $300^{\circ} \mathrm{C}$ to $500^{\circ} \mathrm{C}$ for $15 \mathrm{~min}$ with or without $\mathrm{KrF}$ excimier laser irradiation. Both the diffraction peaks of (100)- and (200)- planes for PZT and LNO were identified at $500^{\circ} \mathrm{C}$. However, (100)- and (200)- peaks for PZT were not observed for the films without laser-irradiation below $400^{\circ} \mathrm{C}$. On the other hand, these peaks were observed for the PZT films with laser-irradiation even below $400^{\circ} \mathrm{C}$. The dielectric constant of the PZT film with laser assisted annealing at $350^{\circ} \mathrm{C}$ was measured to show about 700 . These results demonstrated that the crystallization of ferroelectric PZT thin films was enhanced by KrF excimier laser irradiation and by using the oriented LNO thin film as a seeding layer.
\end{abstract}

(02009 The Ceramic Society of Japan. All rights reserved.

Key-words : PZT, LNO, Excimier laser, Crystallization, Sol-gel, Thin film, Seeding layer

[Received May 12, 2009; Accepted August 20, 2009]

\section{Introduction}

Perovskite-type $\mathrm{Pb}\left(\mathrm{Zr}_{x} \mathrm{Ti}_{1-x}\right) \mathrm{O}_{3}(\mathrm{PZT})$ ceramics and films show excellent piezoelectric and pyroelectric properties, and have been used in many applications such as an actuator and an infrared sensor. Recently, PZT thin films have been attracting much attention for their excellent electrical properties such as high remanent polarization and piezoelectric constants to be applied to a ferroelectric memory and microactuators for MEMS. Therefore, it is desired to deposit the well-crystallized ferroelectric thin films with preferred orientation at low temperatures to be applied to many advanced devices.

Many deposition methods such as sputtering, ${ }^{1)}$ chemical vapor deposition (CVD), ${ }^{2)}$ pulsed-laser deposition (PLD) ${ }^{3)}$ and sol-gel process or chemical solution deposition (CSD) have been used to prepare ferroelectric PZT thin films. To obtain well-crystallized PZT films on a commercially available $\mathrm{Pt} / \mathrm{Ti} / \mathrm{SiO}_{2} / \mathrm{Si}$ substrate, the deposition temperature with the conventional thermal annealing is required over $600^{\circ} \mathrm{C}^{4)}$ The thermal treatment at high temperatures for a long time induces the evaporation of lead oxide from the surface of the films, and causes loss of films' stoichiometry. Therefore, low-temperature crystallization of the ferroelectric thin films is highly required.

CSD is one of the most promising methods because it offers precise control of a composition at a molecular level as well as the molecular design of the precursor and the lower processing temperature. ${ }^{5)}$ Suzuki et al. reported that highly oriented PZT thin films were prepared at $450^{\circ} \mathrm{C}$ with the insertion of interlayer films of a perovskite lead titanate (PT) layer as a transient

Corresponding author: T. Miyazaki; E-mail: miyataka@murata. co.jp seeding layer between each PZT layers. $\left.{ }^{6}\right)$ Han et al. also reported that the sol-gel derived ferroelectric PZT thin film was crystallized at temperatures lower than $400^{\circ} \mathrm{C}$ by using the $\mathrm{CO}_{2}$ laser annealing and a $\left(\mathrm{La}_{0.5} \mathrm{Sr}_{0.5}\right) \mathrm{MnO}_{3}$ (LSMO) electrode layer. ${ }^{7)}$

In this paper, the CSD method with the molecular designed precursor solution was employed to deposit LNO and PZT thin films. The LNO thin films were deposited by the rapid thermal annealing, whereas the PZT thin films were deposited on a Si wafer with the (100)-oriented LNO thin film electrode by laser assisted annealing (LA-A). Surface morphology, phase development, and electrical properties of PZT/LNO films were investigated to evaluate the effect of LA-A and the oriented LNO seeding layer on the low temperature crystallization. A pulsed $\mathrm{KrF}$ excimer laser was used as a laser source for the advantages of high energy density, and selective absorption. The perovskite LNO thin film was selected for a seeding layer as well as a bottom electrode to offer nucleation sites for PZT precursor layers, leading to low processing temperature.

\section{Experimental procedures}

The LNO precursor solution was prepared from lanthanum nitrate $\left[\mathrm{La}\left(\mathrm{NO}_{3}\right)_{3} \cdot 6 \mathrm{H}_{2} \mathrm{O}\right]$, and nickel acetate $\left[\mathrm{Ni}\left(\mathrm{CH}_{3} \mathrm{COO}\right)_{2} \cdot 4 \mathrm{H}_{2} \mathrm{O}\right]$ with a molar ratio of $\mathrm{La}: \mathrm{Ni}=1: 1$. The starting materials were dissolved in 2-methoxyethanol under stirring condition with a concentration of $0.3 \mathrm{M}$. 2-aminoethanol was used to control the film orientation. The PZT precursor solution was prepared from lead acetate tri-hydrate $\left[\mathrm{Pb}\left(\mathrm{CH}_{3} \mathrm{COO}\right)_{2} \cdot 3 \mathrm{H}_{2} \mathrm{O}\right]$, zirconium n-propoxide $\left[\mathrm{Zr}\left(\mathrm{OC}_{3} \mathrm{H}_{7}\right)_{4}\right]$ and titanium iso-propoxide, $\left\{\mathrm{Ti}\left[\left(\mathrm{CH}_{3}\right)_{2} \mathrm{CHO}\right]_{4}\right\}$. Lead acetate tri-hydrate was dehydrated and dissolved in absolute ethanol by refluxing with $\mathrm{NH}_{3}$ flow to obtain $\mathrm{Pb}$-precursor solution, leading to the suppression of the $\mathrm{PbO}$ volatilization during processing. Then titanium and zirconium alkoxides were 
mixed with the Pb-precursor solution to form the PZT precursor solution. Acetyl acetone was used to stabilize the precursor solution. The preparation method of the PZT precursor solution was described elsewhere. ${ }^{5), 6)}$

Deposition of LNO films onto a Si substrate was carried out by spin-coating, and the specimens were dried at $150^{\circ} \mathrm{C}$ for $10 \mathrm{~min}$ and then pyrolyzed at $350^{\circ} \mathrm{C}$ for $10 \mathrm{~min}$ to remove the residual organic compound in the precursor films. Coating was repeated to increase the film thickness up to $250 \mathrm{~nm}$. The crystallization of LNO films was achieved by annealing at $700^{\circ} \mathrm{C}$ for 5 min with $\mathrm{O}_{2}$ flow. The PZT precursor films were spin-coated onto a $\mathrm{Si}$ or $\mathrm{LNO} /$ Si substrate, and the specimens were dried at $110^{\circ} \mathrm{C}$ for $10 \mathrm{~min}$ and then pyrolyzed at temperature ranging from 300 to $420^{\circ} \mathrm{C}$ for 10 min. PZT films of $70 \mathrm{~nm}$ thickness were deposited. The substrate temperatures for the crystallization of PZT films were set up to $500^{\circ} \mathrm{C}$ for $5 \mathrm{~min}$ in air with or without LA-A. The films were irradiated by a pulsed $\mathrm{KrF}$ excimer laser (Lambda Physik, Compex 102) with a wavelength of $248 \mathrm{~nm}$. The output energy per pulse was $190 \mathrm{~mJ}$ at a frequency of $7 \mathrm{~Hz}$. The output beam was directed onto the PZT films without focusing for $15 \mathrm{~min}$. The composition of the $\mathrm{Pb}\left(\mathrm{Zr}_{x} \mathrm{Ti}_{1-x}\right) \mathrm{O}_{3}$ film with $X=0.53$, corresponding to a composition near the morphotoropic phase boundary, was chosen.

The crystalline phases developed during annealing were identified by X-ray diffraction (XRD). Relative permittivity of the resultant films deposited on the silicon wafer with LNO thin film electrode was measured as a function of the frequency using a HP-4284A LCR meter. Surface morphology was observed with an atomic force microscope (AFM). Microstructure was observed with a scanning transmission electron microscope (STEM: Hitachi, Ltd.).

\section{Results and discussion}

\subsection{Phase development}

The phase development during annealing was affected by many factors such as the homogeneity of the precursor solution or sol, ${ }^{6)}$ selection of a seeding layer, ${ }^{5)}$ annealing rate ${ }^{1,8)}$ and temperature, substrates and/or electrodes ${ }^{7)}$ and the amount of excess lead oxide. Therefore, the effect of LA-A on the crystallization of the resultant PZT films on a Si substrate was investigated and shown in Fig. 1. At $500^{\circ} \mathrm{C}$, a faint diffraction peak of PZT (110) was the only peak observed in the film on a $\mathrm{Si}$ substrate with LA-A. This result exhibits that the crystallization of PZT thin films was partially enhanced by LA-A.

The effect of LA-A and the oriented LNO thin films on the crystallization of the resultant PZT film was investigated and

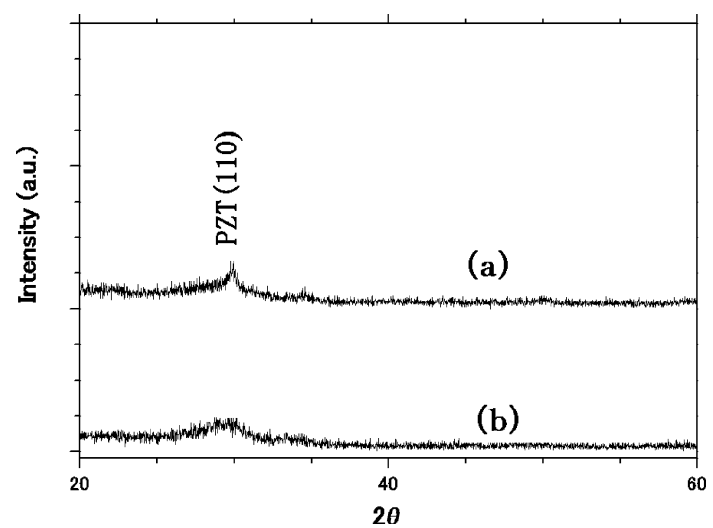

Fig. 1. XRD patterns for the PZT thin film on a Si substrate annealed at $500^{\circ} \mathrm{C}$ for $15 \mathrm{~min}$. (a) with LA-A, (b) without LA-A. shown in Fig. 2, showing the XRD patterns for the PZT/LNO films as a function of annealing temperatures with or without LA-A. At $500^{\circ} \mathrm{C}$, the PZT (100)- and (200)- peaks were identified, as well as the peaks for the LNO of (100)- and (200)- planes. However, (100)and (200) -peaks for PZT became lower as the annealing temperature became lower, and disappeared for the films without laserirradiation below $400^{\circ} \mathrm{C}$. On the other hand, these peaks were observed in those with LA-A even at $350^{\circ} \mathrm{C}$. This result clearly shows that the crystallization of PZT thin films was enhanced with LA-A and the oriented LNO thin film as a seeding layer.

\subsection{Dielectric properties}

Electrical properties of a ferroelectric thin film with a perovskite structure largely depend upon the microstructure and the orientation of the resultant film as well as the electrode on a substrate. ${ }^{9)}$ Figure 3 shows dielectric behavior for the resultant PZT/ LNO thin film capacitors annealed at $350^{\circ} \mathrm{C}$ with or without LAA. The thin film capacitors annealed without LA-A exhibited very low permittivity with high loss because of a amorphous phase and relatively low density. On the other hand, the thin film capacitors annealed with LA-A exhibited relatively high permittivity of about 700. However, dissipation factor of this film was not so low. These results are ascribed to the existence of the amorphous phase with low relative permittivity and/or the smaller crystallite size in the film crystallized at very low temperature.

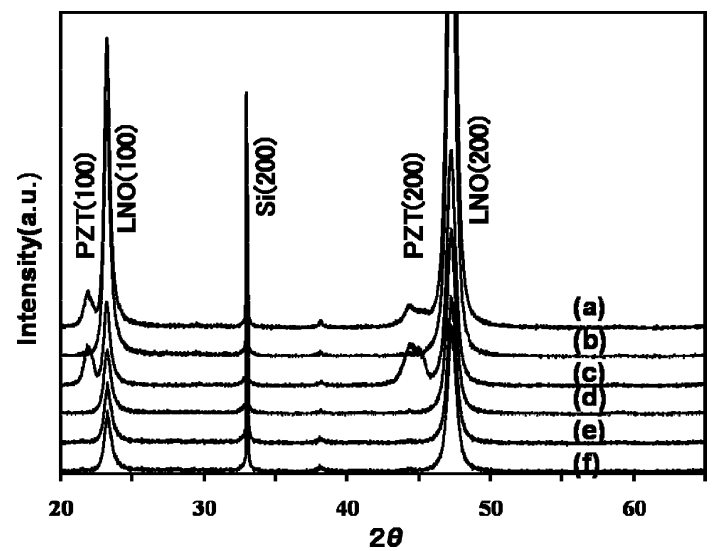

Fig. 2. XRD patterns for the PZT thin films on a $\mathrm{LNO} / \mathrm{Si}$ substrate, annealing at from $300^{\circ} \mathrm{C}$ to $400^{\circ} \mathrm{C}$. (a) at $400^{\circ} \mathrm{C}$ with $\mathrm{LA}-\mathrm{A}$, (b) at $400^{\circ} \mathrm{C}$ without $\mathrm{LA}-\mathrm{A}$, (c) at $350^{\circ} \mathrm{C}$ with $\mathrm{LA}-\mathrm{A}$, (d) at $350^{\circ} \mathrm{C}$ without $\mathrm{LA}-\mathrm{A}$, (e) at $300^{\circ} \mathrm{C}$ with $\mathrm{LA}-\mathrm{A}$, (f) at $300^{\circ} \mathrm{C}$ without LA-A.

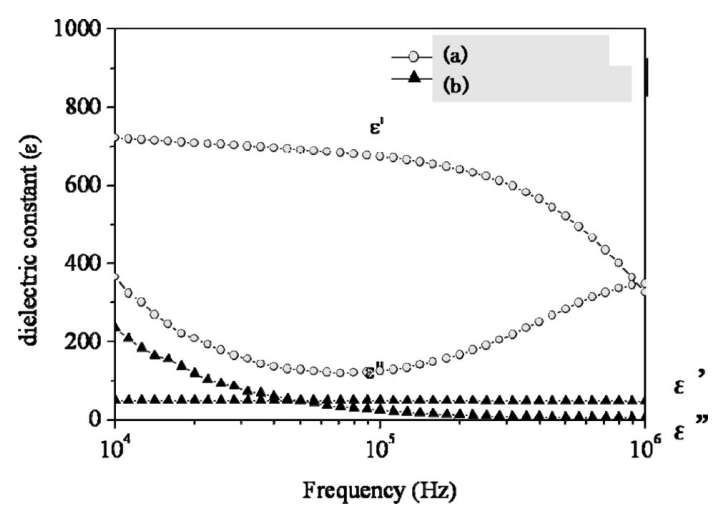

Fig. 3. Dielectric constants of the PZT/LNO thin film capacitors annealed at $350^{\circ} \mathrm{C}$. (a) with LA-A, (b) without LA-A. 


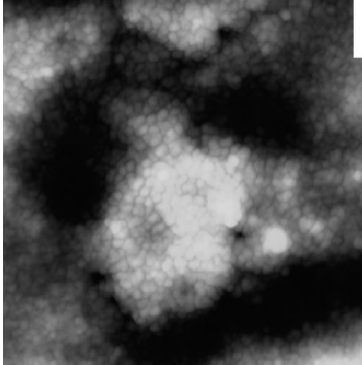

RMS $=13.3 \mathrm{~nm}$

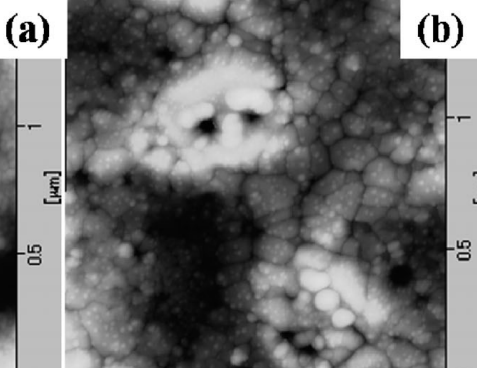

RMS $=11.3 \mathrm{~nm}$

(b)

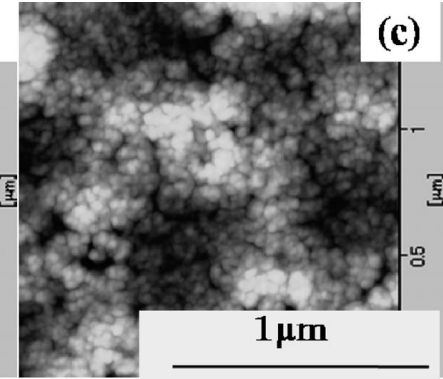

RMS = 6.19 nm

Fig. 4. AFM image of the PZT/LNO thin film capacitors, annealed with LA-A. (a) at $300^{\circ} \mathrm{C}$, (b) at $350^{\circ} \mathrm{C},(\mathrm{c})$ at $400^{\circ} \mathrm{C}$.

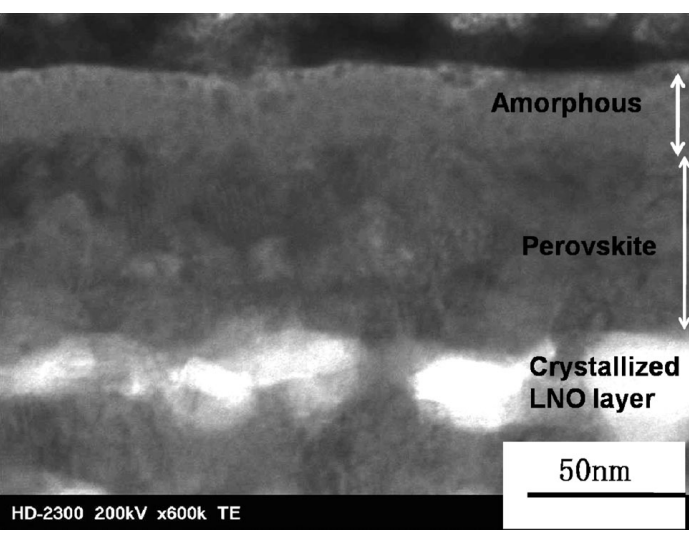

Fig. 5. TEM image of a transverse section through the PZT/LNO interface of the film, annealed at $350^{\circ} \mathrm{C}$ with $\mathrm{LA}-\mathrm{A}$

\subsection{Microstructure}

Figure 4 shows the AFM images for the PZT/LNO thin films as a function of annealing temperatures. As annealing temperature increased, surface roughness (RMS) became smaller. Figure 5 exhibits a TEM image for a cross-sectional part of a transverse section through the PZT/LNO interface of the film, annealed at $350^{\circ} \mathrm{C}$ with LA-A. Columnar grains of LNO are clearly observed, and the columnar grains of PZT with a size approximately in the range from 20 to $50 \mathrm{~nm}$ were identified just above the LNO layer. However, the TEM image also reveals that there is a thin layer of second phase at the film surface consisted of a nanocrystalline or amorphous phase.

Many researchers have studied the formation mechanisms of the preferred orientation of PZT films on a Pt bottom electrode. ${ }^{9), 10)}$ These papers have shown that the orientation of PZT films was affected by many factors such as heating treatments, ${ }^{8), 11), 12)}$ their $\mathrm{Pb}$ content, deposition methods, ${ }^{3), 13)}$ nucleation of perovskite phase which, in some cases, originated from $\mathrm{PZT} / \mathrm{Pt}$ interface, ${ }^{3), 10), 11)}$ and the other case, nucleated from $\mathrm{Pt}$ crystals or transient phases of $\left(\mathrm{Pt}_{x} \mathrm{~Pb}, \mathrm{PbO}\right)$, because of the good lattice matching between them. ${ }^{8), 14)}$ The formation of the (100)preferred orientation of perovskite phase in the PZT films was mainly attributed to the effects of both the local epitaxy from seeding layers and the crystal growth rate which depended on the crystal orientation. ${ }^{10)}$ Hence, it was assumed that the (100)oriented LNO layer acted as a nucleation site and induced the (100)- and/or (001)-orientation for perovskite phase because of the good lattice matching between them.

Excimer laser has been widely used for annealing of thin films, of which crystallisation temperatures are higher than those temperatures where the substrates can withstand. Many researchers have studied the crystallization mechanisms of PZT thin films with excimer laser annealing. ${ }^{15-19)}$ These papers have shown that the improvements in crystallinity of PZT films depends on substrates, ${ }^{16)}$ frequency and the laser pulse energy density ${ }^{18)}$ and film thickness. ${ }^{19)}$ For the low temperature annealing with a laser irradiation, optical absorption coefficient of substrates is also very important as well as the lattice matching between the substrates and perovskite phase. It is also reported that there is appropriate energy density and frequency of the laser pulse for the low temperature crystallization. ${ }^{18)}$ The optimum energy density of laser was reported to be about $100 \mathrm{~mJ} / \mathrm{cm}^{2}$, because surface damage was induced if the laser pulse energy density was higher than the optimum energy density. Hence, it was assumed that LNO layer also absorbed laser irradiation to enhance the low-temperature crystallization of PZT thin films. The laser pulse energy density used in this study was not optimized. Therefore, the crystallization temperature of the PZT thin film is expected to be lowered if the laser pulse energy density is optimized.

\section{Conclusions}

PZT thin films with a composition $(\mathrm{Zr} / \mathrm{Ti}=53 / 47)$ near MPB and $\mathrm{LaNiO}_{3}$ (LNO) thin films were deposited by the chemical solution deposition (CSD) method on a $\mathrm{Si}$ or $\mathrm{LNO} / \mathrm{Si}$ substrate, with or without LA-A.

(1) Crystallization of the ferroelectric PZT thin films were enhanced with $\mathrm{KrF}$ excimer laser irradiation and with the oriented LNO thin film as a seeding layer.

(2) Dielectric behavior for the PZT/LNO thin film capacitor was also investigated. The PZT/LNO thin film capacitor annealed at $350^{\circ} \mathrm{C}$ with laser-irradiation exhibited relative permittivity of about 700. However, dissipation factor of the resultant film was relatively high. This result suggested the existence of phase with low relative permittivity.

Further investigation to optimize the laser pulse energy density is essential to deposit the ferroelectric thin films with enough electrical properties at very low temperatures.

\section{References}

1) C. V. R. Vasant Kumar, M. Sayer, R. Pascual, D. T. Amm, Z. Wu and D. M. Swanston, 58, 1161-1163 (1991).

2) K. Kotani, K. Tako, S. Kuroki and T. Ito, IEICE Technical Report, 277 (2006).

3) Z.-J. Wang, R. Maeda, M. Ichiki and H. Kokawa, Jpn. J. Appl. Phys., 40, 5523-5527 (2001).

4) K. Aoki, Y. Fukuda and A. Nishimura, Jpn. J. Appl. Phys., 32, 4147-4149 (1993).

5) H. Suzuki, S. Kaneko, K. Murakami and T. Hayashi, Jpn. J. 
Appl. Phys., 5803-5807 (1997).

6) H. Suzuki, T. Koizumi, Y. Kondo and S. Kaneko, J. Euro. Ceram. Soc., 19, 1397-1401 (1999).

7) H.-C. Pan, C.-C. Chou and H.-L. Tsai, Appl. Phys. Lett., 83, 3156-3158 (2003).

8) K. G. Brooks, I. M. Reaney, R. Kissurska, Y. Huang, L. Bursill and N. Setter, J. Mater. Res., 9, 2540-2553 (1994).

9) Z. J. Wang, J. R. Chu, R. Maeda and H. Kokawa, Thin Solid Films., 416, 66-71 (2002).

10) Y. Liu and P. P. Phule, J. Am. Ceram. Soc., 79, 495-498 (1996)

11) C.-C. Hsueh and M. L. Mecartney, J. Mater. Res., 6, 22082217 (1991).

12) C. W. Law, K. Y. Tong, J. H. Li and K. Li, Thin. Solid. Films., 335, 220-224 (1998).
13) Z. J. Wang, H. Kokawa and R. Maeda, J. Cryst. Growth, 262, 359-365 (2004).

14) I. M. Reaney, K. Brooks, R. Kissurska, C. Pawlaczyk and N. Setter, J. Am. Ceram. Soc., 77, 1209-1216 (1994).

15) Y. Miyamoto, T. Tsuchiya, I. Yamaguchi, T. Manabe, H. Niino, A. Yabe, T. Kumagai, T. Tsuchiya and S. Mizuta, Appl. Surf. Sci., 197-198, 398-401 (2002).

16) T. Tsuchiya, I. Yamaguchi, T. Manabe, T. Kumagai and S. Mizuta, Mat. Sci. Semicon. Proc., 5, 207 (2002).

17) T. Tsuchiya, I. Yamaguchi, T. Manabe, T. Kumagai and S. Mizuta, Mater. Sci. Engi., B, 109, 131 (2004).

18) P. P. Donohue, M. A. Todd and Z. Huang, Integrated Ferroelectrics, 51, 39-49 (2003).

19) X. M. Lu, J. S. Zhu, W. S. Hu, Z. G. Liu and Y. N. Wang, Appl. Phys. Lett., 66, 2481-2483 (1995). 